\title{
ADVOCACY FATIGUE: SELF-CARE, PROTEST, AND EDUCATIONAL EQUITY
}

\section{Carrie Griffin Basas*}

Much of the literature in education has focused on the experiences of teachers and school leaders as they encounter students with individualized or "special" learning needs and their families. This body of literature places the professional at the center of its concern by studying such phenomena as burnout and compassion fatigue. In this article, the Author argues that this vigilance for the experience of schools has overlooked the material, psychological, and social impact on families that must advocate for their students in the U.S. educational system. Examining educational conflicts that occur in special education and English Language Learner [ELL] settings, the Author defines this "advocacy fatigue" as the increased strain on resources that comes from continued exposure to system inequities and inequalities. In the final section of the Article, she identifies strategies for collaboratively addressing educational equity that range from resistance to self-care, community wholeness to professional development.

Une bonne partie de la littérature en matière d'éducation a été consacrée aux expériences que vivent les enseignants et les directeurs d'école lorsqu'ils doivent interagir avec des élèves ayant des besoins d'apprentissage individuels ou "spéciaux» et leurs familles. Cette littérature place le professionnel au cour des préoccupations en mettant l'accent sur des phénomènes comme l'épuisement professionnel et l'usure de compassion. Dans cet article, l'auteure déplore que l'on ait ainsi occulté les répercussions matérielles, psychologiques et sociales auxquelles font face les familles qui doivent défendre les intérêts de leurs enfants dans le système d'éducation américain. Examinant les conflits pédagogiques qui surviennent dans les milieux de l'éducation spécialisée et de l'apprentissage de l'anglais [ELL], l'auteure définit le phénomène qu'elle appelle "advocacy fatigue" ("usure de défense ») comme l'intensification des pressions exercées sur les ressources par suite de l'exposition constante aux iniquités et inégalités du système. Dans la dernière section de l'article, l'auteure propose différentes stratégies visant à promouvoir l'équité pédagogique par la collaboration, notamment la résistance à l'autothérapie, la promotion du bien-être collectif et le perfectionnement professionnel.

JD, Harvard Law School (2002), M Ed (2015) University of Washington. She would like to thank Elizabeth Pendo, Stephen Rosenbaum, Laverne Jacobs, Joy Williamson-Lott, Mike Knapp, and symposium attendees for comments on this draft, as well as Emma Gilchrist for assistance with background research. 


\section{INTRODUCTION}

To achieve educational equity in our public schools that strikes at both equal opportunities and outcomes, schools and communities must take into consideration the environments in which students learn, the diversity of special education and general education, and how experiences of inclusion and integration affect student growth. ${ }^{1}$ Inclusion can be defined as:

providing to all students, including those with significant disabilities, equitable opportunities to receive effective educational services, with the needed supplementary aids and support services, in age-appropriate classrooms in their neighborhood schools, in order to prepare students for productive lives as full members of society. ${ }^{2}$

The need for self-advocacy and community organizing toward inclusion as educational equity is a constant in the lives of people on the social margins, such as Limited English Proficient families, students in special education, and students of color. As Jan Nespor and David Hicks have explored, individuals in these situations become de facto sources of policymaking, yet the energy required by such roles and the very structure of schools, drive an individual focus on individual resolution rather than systemic change. ${ }^{3}$ Rights enforcement brings a game of attrition through conflict that could ultimately end in litigation. In these high-tension situations where parents and students are torn between individual resolution and collective action, issues that already mark their lives come into full relief. ${ }^{4}$ Families' limited economic means, inadequate community supports, and physical and emotional resources need to be leveraged at the same time that they are experiencing confusion, stress, and fear. ${ }^{5}$ The relationship between the family and the school community becomes a defensive one at best, and can become even more complicated when students are not white or native English speakers.

While the concept of burnout has been explored in part under the term "compassion fatigue" in fields such as social work, teaching, and nursing, I view it broadly and inclusively. Other scholars have focused their work on the negative effects of crisis and care-giving on professionals paid to do that kind of work, particularly teachers and school administrators. ${ }^{6}$

1 J S De Valenzuela, Susan R Copeland \& Cathy Huaqing Qi, "Examining Educational Equity: Revisiting the Disproportionate Representation of Minority Students in Special Education" (2006) 72 Exceptional Children 425 at 425.

2 National Center on Educational Restructuring and Inclusion (NCERI), "National Study of Inclusive Education", online: (1994) 15, available at <http://files.eric.ed.gov/fulltext/ED375606.pdf>.

3 Jan Nespor \& David Hicks, "Wizards and Witches, Parent Advocacy and Contention in Special Education in the USA" (2010) 25:3 J Education Policy 309 at 311.

$4 \quad$ Ibid at 309-10.

5 Jasmine Lavine, "Some Thoughts From a "Minority" Mother on Overrepresentation in Special Education", (2010) 30:2 Disability Studies Quarterly online: <http://dsq-sds.org/article/view/1238/1283>.

6 See e.g., Ginny Sprang, James Clark \& Adrienne Whitt-Woosley “Compassion Fatigue, Compassion Satisfaction, and Burnout: Factors Impacting a Professional's Quality of Life” (2007) 12:3 J Loss \& Trauma: International Perspectives on Stress \& Coping 259 at 260; Antonia Papastylianou, Maria Kaila \& Michael Polychronopoulos, “Teachers’ Burnout, Depression, Role Ambiguity and Conflict” (2009) 12:3 Social 
While those concerns should inform education policy and professional training, emphasis on providers has left out the traumas of discrimination and resource limitations that affect students, families, and the surrounding community in educational conflicts, as well. As families serve as the primary advocates and de facto policymakers for their students through much of their children's school careers, they will be my primary unit of analysis in this paper. As I will argue, burnout, compassion fatigue, or even concepts such as "secondary trauma" and "litigation stress", are too limited in their current focus to holistically capture families' realities. Rather, these concepts provide just one piece of understanding educational advocacy and from a particular perspective.

Using a disability studies perspective, I will first provide an overview of areas of tension in United States education as they relate to two marginalized student populations - students in special education and English Language Learner [ELL] programs - and show how their individual experiences (and those of their families') has thus far been captured by the scholarly literature. I have selected these two populations because of overlapping, but not identical, forms of marginalization in schools, including shared experiences of being disadvantaged in asserting rights, differences in intra-community cultural pride that conflict with often negative views of school leaders about differences as deficits, and similar experiences of resource strain in navigating school systems. Both students with disabilities and emerging bilingual learners require specialized education. These populations can come into conflict with schools over both resources and perspectives (and misconceptions) about their experiences.

Disability studies is a useful tool for understanding more than disability as traditionally characterized. Rather, this lens assists us in critiquing how approaches to human variation in schools - whether abilities or language - can trigger the sorting, classifying, and marginalizing individuals and groups of people. ${ }^{7}$ I will demonstrate that the focus on professional care-giving and burnout in the literature reinforces views of these students and families on the margins that have greater access needs to specialized education as dependent, troublesome, or adversarial. ${ }^{8}$ Then I will define "advocacy fatigue" as the increased strain on emotional, physical, material, social, and wellness resources that comes from continued exposure to system inequities and inequalities. To do this, I will draw on such fields as psychology, education policy, gender studies, critical race theory, and socio-legal studies. I will conclude by presenting examples of strategies for collaboratively responding to advocacy fatigue that encompass both resistance to inequalities within the system, as well as structural shifts that embed notions of self-care and community wholeness.

Psychology of Education 295; Barry A. Farber, Crisis in Education: Stress and Burnout in the American Teacher (San Francisco: Proquest Info \& Learning, 1991).

7 Katharina Heyer, "A Disability Lens on Sociolegal Research: Reading Rights of Inclusion from a Disability Studies Perspective" (2007) 32:1 L \& Social Inquiry 261 at 264.

8 Donna Lero, Carolyn Pletsch \& Margo Hilbrecht, "Introduction to the Special Issue on Disability and Work: Toward Re-Conceptualizing the "Burden" of Disability", online: (2012) 32:3 Disability Studies Quarterly, available at $<$ http://dsq-sds.org/article/view/3275/3108> (highlighting how constructions of disability "lead to social exclusion and dependence, as individuals with disabilities are often identified as a 'burden' to society"). 


\section{INTRODUCTION TO THE PROBLEM: TENSIONS IN AMERICAN EDUCATION AND EDUCATORS}

\section{A. Tensions in Education: On the Margins}

For purposes of this Article, I focus the lens on where tensions arise in K-12 education in the United States as these conflicts relate to marginalized students specifically, and thus, by extension, their families pushed into advocacy roles. Here, I have chosen English Language Learners and students with disabilities in special education ${ }^{9}$ as the examples that frame the theoretical analysis. English Language Learners, sometimes referred to as emerging bilingual learners, constituted $9.1 \%$ of public school enrollment in 2011-2012. ${ }^{10}$ Students in special education constituted about $14 \%$ of the overall student enrollment in public schools. ${ }^{11}$ Both groups constitute strong minority presences that push the existing public school system to do more and to think with nuance about meeting individual student development and access needs. These populations can, and in fact, do overlap in the school system functionally. For example, schools sometimes place English Language Learners in special education for "language disabilities" rather than providing bilingual classroom support. Special education students, rightly identified and placed, might also be English Language Learners that have disability support needs beyond language acquisition. In the United States, for example, one growing area of special education is providing services to students that have complex trauma experiences and exacerbated health conditions because they immigrated from countries with active wars, genocides, and/or minimal health care systems. ${ }^{12}$

These two groups make effective examples of marginalized student experiences as they relate to the need for parental and student advocacy because both student populations are often in high conflict relationships with schools and administrators, and are at risk for having their needs unmet. Occupying this status limits their opportunities to learn and to achieve at rates of native English speakers and non-disabled peers. ${ }^{13}$ Policymakers and administrators, as well as the popular media, can depict the path toward achieving educational equity in these areas as impossible: one of "nightmarish proportions" or "out-of-control" monsters. ${ }^{14}$ In educating both populations, teachers often feel unprepared to meet their needs, ${ }^{15}$ and that strain can contribute to greater placement and teaching practices that isolate and marginalize these students. While

9 Research about the intersection of these two populations is emerging, with states reporting rates of 0 to over $17 \%$ for ELL students in special education. Amanda L Sullivan, "Disproportionality in Special Education Identification and Placement of English Language Learners" (2011) 77:3 Exceptional Children 317 at 319. National Center for Education Statistics, Fast Facts: English Language Learners, online: Institute of Education Sciences $<$ http://nces.ed.gov/fastfacts/display.asp?id=96>.

11 National Center for Education Statistics, Fast Facts: Students with Disabilities, online: Institute of Education Sciences <http://nces.ed.gov/fastfacts/display.asp?id=64> [NCES, Disabilities].

12 Judit Szente, James Hoot \& Dorothy Taylor, "Responding to the Special Needs of Refugee Children: Practical Ideas for Teachers" (2006) 34:1 Early Childhood Education Journal 15; Festus E Obiakor, Multicultural Special Education: Culturally Responsive Teaching (Pearson, 2007).

13 Sullivan, supra note 8 at 317-18.

14 Beth Ferri, "Voices in the Struggle: In Response to “"Reining In' Special Education”, online: (2006) 26:2 Disability Studies Quarterly <http://dsq-sds.org/article/view/681/858>.

15 Sullivan, supra note 8 at 330. 
school leaders might perceive these student groups as small fractions of their overall learning community, the reality is that students that are linguistically diverse are an ever-growing population. ${ }^{16}$ The same is true for students with certain kinds of disabilities, such as autism, developmental delays, and "other health impairments." 17

Some other shared issues between these populations include the limited availability of specialized services, nuances in placement, and schools' concerns about legal compliance. ${ }^{18}$ Often, both groups are perceived as posing problems rather than opportunities for schools to adapt to new ways of teaching and learning. ${ }^{19}$ Both emergent bilingual and special education students present special learning needs that schools and districts might not be prepared to meet because of lack of teacher or administrator experience, limited resources, or competing demands between student needs. ${ }^{20}$

One effect of this lack of expertise or resources is disproportionality. ${ }^{21}$ Scholars have explored this issue in special education, where students of color and English Language Learners, for example, are incorrectly over- or under-placed in special education because of the misidentification of their needs based on poor testing, stereotypes and biases, and lack of appropriate available services. ${ }^{22}$ Other factors influencing this phenomenon include student poverty, minority teacher hiring, the history and politics of school desegregation, teacher credentialing, and minority student enrollment. ${ }^{23}$ Disproportionality extends beyond special education to encompass school placement decisions, discipline decisions, dropout rates, and academic performance results. ${ }^{24}$ Most concerning is evidence that suggests that students receive a diminished quality of education in restrictive settings and are therefore further disadvantaged in their learning and development. ${ }^{25}$

A second effect of schools struggling with placement and services is the tension between segregating students with special language or learning needs from the general student population, or striving towards inclusion and integration. ${ }^{26}$ Schools might perceive that their ELL or special

\footnotetext{
Ibid at 317.

NCES, Disabilities supra note 11.

Erin Archerd, “An IDEA for Improving English Language Learners’ Access to Education” (2013) 41 Fordham Urb LJ 351 at 351, 355, 360.

19 See, e.g., Mariela A Rodriguez \& Iliana Alanis, "Negotiating Linguistic and Cultural Identity: One Borderlander's Leadership Initiative" (2011) 14:1 Intl J of Leadership in Education 103 at 104 (identifying an "educational culture that deems ... native language a deficit and a drain on an educational system and that persistently privileges English"); Ferri, supra note 14.

21 National Education Association, "Truth in Labeling: Disproportionality in Special Education” (2007), online: National Centre for Culturally Responsive Educational System

$<$ http://www.nccrest.org/Exemplars/Disporportionality_Truth_In_Labeling.pdf $>$.

22 Sullivan, supra note 8 at 318.

23 Ibid at 318-19; De Valenzuela et al, supra note 1 at 426.

24 Sullivan, supra note 8 at 318.

25 De Valenzuela et al, supra note 1 at 426.

26 Some of the barriers identified to inclusion are: pace and content, expectations of independent study skills, high stakes testing, negative teacher attitudes, the lack of knowledge about special education or ELL instruction, poor collaboration between specialized teachers and general education teachers, lack of administrator support,
} 
education students are best served in separate classrooms, for the most part, where staff with expertise can concentrate on meeting their educational needs. ${ }^{27}$ This philosophical orientation is not without its negative effects. We know that students of color are more likely to be educated in restrictive environments than their white peers, particularly where a district has a high rate of minority student enrollment. ${ }^{28}$ However, what we also need to know through further research and data collection is how this phenomenon extends to ELL students, particularly where those students are not white. ELL students, for example, often spend at least part of their school day in a separate setting, as do many students in special education who are not ELL. ${ }^{29}$ However, while serving students where they can receive the extra support that they need is a best practice in education, those services can often be delivered in integrated classrooms where neither students with disabilities nor students becoming bilingual in English will suffer from isolation from their peers or reduced quality of educational challenges. ${ }^{30}$

Here, perception is also key to understanding inertia within the system for meeting the needs of both special education and ELL students. As the National Center for Universal Design for Learning emphasizes, moving to a mode of flexible and responsive universal design in learning-recognizing that students need "multiple means of representation"/ "the 'what' of learning", "multiple means of action and expression"/“the "how' of learning", and "multiple means of engagement"/ "the "why' of learning" 31 _ actually serves both the needs of students with disabilities and students learning English, while providing multiple ways of grasping information for students without disabilities or particular language needs. ${ }^{32}$ Thus, the overemphasis on separate as being most equal is undercut by the experiences of all students receiving more accessible instruction. Yet, this perception of a zero-sum game persists and reinforces divides between teachers and student populations.

Finally, as schools and teachers on the ground attempt to navigate how to serve these two diverse student populations, they can encounter complicated webs of legal compliance. ${ }^{33}$ Zirkel and Lupini have described this phenomenon as the "legalization" of public education. ${ }^{34}$ While the National Association of Secondary School Principals [NASSP] and some states identify legal

and limited instructional strategies. Jamie L Worrell, "How Secondary Schools Can Avoid the Seven Deadly

School "Sins" of Inclusion" (2008) 36:2 American Secondary Education 43.

27 National Education Association, supra note 21 at 9.

28 De Valenzuela et al, supra note 1 at 427.

29 Sullivan, supra note 8 at 324; De Valenzuela et al, supra note 1 at 435 (finding that minority students and English Language Learners were disproportionately enrolled in special education and placed in more segregated environments than white or English-native students).

30 National Education Association, supra note 21 at 9; De Valenzuela et al, supra note 1 at 437.

31 National Center for Universal Design for Learning, "About UDL”, online: National Center for Universal Design for Learning < http://www.udlcenter.org/aboutudl/whatisudl >.

32 National Center for Universal Design for Learning, "FAQs from the National UDL Task Force", online: National Center for Universal Design for Learning $<$ http://www.udlcenter.org/advocacy/faq_guides/ell\#question1 $>$.

33 See Archerd, supra note 18 at 363-71 (discussing schools' respective legal requirements under the Individuals with Disabilities in Education Act ("IDEA") and the Equal Education Opportunities Act ("EEOA")).

34 William Lupini \& Perry Zirkel, "An Outcomes Analysis of Education Litigation" (2003) 17:2 Educational Policy 257 at 258. 
competency as a value for teachers and administrators, few states require training-particularly advanced understandings — of school law as part of pre-service, degree requirements, or ongoing professional development. ${ }^{35}$ Placing teachers and school administrators in the roles of de facto lawyers can enhance anxiety and conflict in the system, particularly in interactions with families and students. ${ }^{36}$ These conflicts are most robust in the areas of serving special education students and English Language Learners. A recent study of principals' legal literacy, conducted by Militello, Schimmel, and Eberwein, demonstrated that over $41 \%$ of principals received annual legal threats from parents with special education or limited English proficiency students and 7\% of the principals received these kinds of threats weekly. ${ }^{37}$ About $25 \%$ of principals spent 3 or more hours every week attempting to avoid litigation, and about another $50 \%$ of them spent at least 1-2 hours a week engaged similarly. ${ }^{38}$ Beyond providing advice to teachers regarding liability for student injuries, principals next spent their time advising teachers on the area of special education and legal compliance. ${ }^{39}$ This issue was also the area that principals identified as being the weakest of teacher knowledge about the law and it was their main concern for improving legal literacy. ${ }^{40}$ Being forced to operate in this chasm of understanding legal compliance can cause overload, avoidance, and denial; ultimately, conversations between families and schools shut down. ${ }^{41}$

\section{B. Traditional Approach to the Problem of Conflict: Provider Perspective}

The preceding discussion, like much of the current conversation in education about these groups, emphasizes the issues that schools face in managing the needs of ELL and special education students. This tendency among researchers and scholars to view conflict at school from the personnel perspective is also common in other fields, such as psychology, social work, and medicine. ${ }^{42}$ Teaching is a high-stress helping field because "it involves close relationships with other people, requires speed in decision-making and the decisions taken might have a serious economic, social or other impact on the lives of those involved."43 Existing approaches

35 Matthew Militello, David Schimmel \& Jake Eberwein, "If They Knew, They Would Change: How Legal Knowledge Impacts Principals' Practice" (2009) 93:1 NASSP Bulletin 27 at 29.

36 See e.g., Bruce Meredith \& Julie Underwood, "Irreconcilable Differences? Defining the Rising Conflict Between Regular and Special Education" (1995) 24 JL \& Educ 195 at 198-99 (providing a framework for understanding the fundamental conflicts between special education and general education as the former for focusing on individual students, parental empowerment, legal accountability, and federal control, versus general education with its focus on group outcomes, community empowerment, political accountability, and state and local control).

37 Militello et al, supra note 35 at 37.

38 Ibid at 38.

39 Ibid at 39.

40 Ibid at 40

41 See generally David Schimmel, Suzanne Eckes \& Matthew Militello, Principals Teaching the Law: 10 Legal Lessons Your Teachers Must Know (Thousand Oaks, CA: Corwin Press, 2010) (providing a proactive strategy to educate teachers about areas of substantive and procedural compliance with school law).

42 Sara Maltzman, "An Organizational Self-Care Model: Practical Suggestions for Development and Implementation" (2011) 39:2 The Counseling Psychologist 303 at 304.

43 Papastylianou et al, supra note 6 at 296. 
in the helping professions attempt to capture the strain that providers experience to better improve environments and practices, ultimately, for students. Such labels as "compassion fatigue", "burnout" well-being and the secondary effects of trauma. With each of these constructs, the primary focus has been on supporting and assisting individuals rather than addressing systemic change. ${ }^{47}$

\section{Compassion Fatigue}

"Compassion fatigue" is when professionals working with trauma survivors experience a secondary form of trauma in the process of relating to their clients, patients, or students. ${ }^{48}$ They are emotionally affected and can be transformed by the other person's experiences, almost as if they are the ones experiencing the original injury. ${ }^{49}$ Repeated exposure to trauma can result in post-traumatic stress disorder-like symptoms in which the caregiver's capacity to provide help and support or to relate to others becomes diminished. ${ }^{50}$ Working in a profession that once provided satisfaction from its emphasis on empathy ("compassion satisfaction") can convert to "compassion stress" quickly, and finally, "compassion fatigue.".51 Professionals experiencing a sense of satisfaction, having peer support, and finding strategies to disengage from emotional trauma can mitigate compassion fatigue and focus on the satisfying elements of relating to others. $^{52}$

\section{Burnout}

While some researchers have characterized "burnout" as a feature of compassion fatigue, ${ }^{53}$ pioneers Maslach, Schauefeli and Leiter have argued that it has three components: exhaustion, cynicism, and inefficacy. ${ }^{54}$ According to this literature, burnout looks like a stress-induced "emotional and cognitive distancing from work-related tasks" that is accompanied by

44 Richard Adams, Joseph A Boscarino \& Charles Figley, "Compassion Fatigue and Psychological Distress Among Social Workers: A Validation Study" (2006) 76:1 The American Journal of Orthopsychiatry 103; Brian E Bride, Melissa Radey \& Charles Figley, "Measuring Compassion Fatigue" (2007) 35 Clinical Social Work J 155; Kyle Killian, "Helping Till It Hurts? A Multimethod Study of Compassion Fatigue, Burnout, and Self-Care in Clinicians Working with Trauma Survivors" (2008) 14:2 Traumatology 32.

45 Christina Maslach, Wilmar Schaufeli \& Michael Leiter, "Job Burnout” (2001) 52 Annual Review of Psychology 397; Papastylianou et al, supra note 6; Brian Perron \& Barbara Hiltz, "Burnout and Secondary Trauma Among Forensic Interviewers of Abused Children" (2006) 23:2 Child \& Adolescent Social Work J 216.

49 Ibid.

$50 \quad$ Adams et al, supra note 44 at 104-05.

51 Sprang et al, supra note 6 at 260.

52 Ibid at 261, 271-72.

53 Adams et al, supra note 44 at 103-04.

54 Maslach et al, supra note 45 at 402. 
"depersonalization" and "lower productivity and feelings of incompetence." $" 55$ Burnout can lead to depression.

For my purposes, I view burnout as an extreme form of compassion fatigue. In the teaching profession, its causes look much like those of compassion fatigue, just with greater conflict and heightened effects on the professional environment of schools: role conflicts with administrators, pressures from leadership, frustrated professional growth, lack of support and resources, poor dynamics with colleagues, low pay, challenging student behavior, strained parent relations, poor communication, and a diminished sense of autonomy. ${ }^{56}$ Sometimes, professionals experiencing burnout leave their chosen profession or remain in it only to feel animosity toward coworkers or the population they are serving (e.g., students, patients, clients). ${ }^{57}$ Researchers have found that the exhaustion feature of burnout - the lack of energy-is the most telling one among teachers. ${ }^{58}$ School leadership can begin to address burnout by clarifying teacheradministrator roles, increasing avenues of communication, making "reciprocal" investments in teachers and their development, and emphasizing teachers' independence and contributions. ${ }^{59}$

\section{Litigation Stress}

The third example of viewing stressors from the perspective of professionals is litigation stress. This example is also one that might be a bridge between the lessons of compassion fatigue and burnout, with their focus on individual supports, to understanding the mutual stresses that both helping professionals and the clients they serve experience. ${ }^{60}$ Litigation stress is arguably multi-dimensional. On the one hand, the term recognizes the presence of systemic tendencies toward conflict - the sort of "adversarial legalism" that pervades the courts and trickles down into social relations and informal resolution of conflicts, as well. ${ }^{61}$ Yet, litigation stress also nods to the effects on individuals - such as the judges and lawyers involved in cases, particularly ones that are high stakes or are protracted over many years in their resolution. ${ }^{62}$ Defending against a case also creates psychological strain. For example, in advising school leaders on how to approach a lawsuit, Shoop and Dunklee suggest that they should expect to feel at a disadvantage because they "don't know all the rules, and therefore, lack meaningful control of their destinies. ${ }^{.63}$ Principals and teachers are at a particular disadvantage in managing this

\footnotetext{
Maltzman, supra note 42 at 306.

Papastylianou et al, supra note 6 at 296-97.

Ibid at 296.

Ibid at 297.

Ibid at 297, 299, 301.

60 Tamara Relis, "Civil Litigation from Litigants' Perspectives: What We Know and What We Don't Know About the Litigation Experience of Individual Litigations" (2002) 25 Studies in Law, Politics and Society 151 at 152.

61 See generally Robert Kagan, "Adversarial Legalism and American Government" (1991) 10:3 Journal of Policy Analysis and Management 369 (explaining how this approach is lawyer-dominated and provides for a complex, formal, costly, invasive, and obscure system for plaintiffs to navigate).

62 See Peter G Jaffe et al, "Vicarious Trauma in Judges: The Personal Challenge of Dispensing Justice" (2003) 54:4 Juvenile \& Family Court J 1 at 1(discussing the coping strategies of judges in processing the traumas they see in their courtrooms).

63 Robert J Shoop \& Dennis R Dunklee, Anatomy of a Lawsuit: What Every Education Leader Should Know About Legal Actions (Corwin, 2006) at 79-80.
} 
stress because of their lack of training in how litigation unfolds and their tendency to internalize a lawsuit as an indictment of their professionalism and ethics. ${ }^{64}$

Marshall, Picou, and Schlichtmann have approached litigation stress from yet another perspective-realizing the toll that the adversarial process takes on plaintiffs that have already experienced a trauma. Such litigants will continue to relive and re-enact that trauma through the courts and experience the unique traumas that bearing witness, being questioned about one's truths, and fighting with unequal resources brings in that setting. ${ }^{65}$ Others working in the field have called the litigation process itself a "trauma" where "individuals who bring suit may endure injury from the very process through which they seek redress." ${ }^{66}$ Lees-Haley, Cohen, and Vesper have expanded that concept into arguing for recognizing new psychological disorders

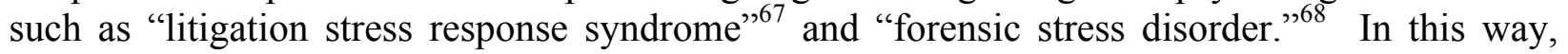
litigation stress is less about the secondary effects of work and more about the primary traumas caused by interacting with a system that places adversarialism at its core. As Marshall and others note, protracted, contested litigation also causes upheaval in and damage to communities, where others affected by the outcome of the case wait in limbo. ${ }^{69}$ Essentially, such conflict is a form of retraumatization.

\section{SHIFTING PERSPECTIVES: EFFECTS ON FAMILIES, STUDENTS, AND THE SURROUNDING COMMUNITY}

\section{A. Gaps in the Literature}

The preceding discussion emphasizes that fields such as education, psychology, and social work have natural tendencies to consider the effects of their work internally on their own professionals. They ask-How will the stress of the school environment affect us as professionals? This kind of response in a field so focused on professionalization is selfprotective, but not entirely flawed because students and families need school leaders and staff to engage in self-care and reflection so that they can focus on their work, have energy left to improve professionally, and be consistent in their attendance and engagement. This kind of selfprotective response also forecloses asking the question of whether professionalism in teaching and school administration is entirely good - or whether connecting emotionally to families and communities should be a desirable part of the work.

The literature in education, in particular, is void of a robust understanding of how compassion fatigue, burnout, and litigation stress, for example, might apply conceptually to the experiences of parents and students - and how these experiences might further disadvantage or thwart mutual efforts for educational equity. Teachers and principals are not the only people engaged in

\footnotetext{
Ibid at 100-01.

Marshall et al, supra note 46 at 291-92.

Larry Strasburger, "The Litigant-Patient: Mental Health Consequences of Civil Litigation" (1999) 27:2 The J

American Academy Psychiatry \& L 203 at 204.

Paul R Lees-Haley, "Litigation Response Syndrome” (1988) 6:1 American J Forensic Psychology 3 at 3-4.

68 Larry Cohen \& Joyce Vesper, "Forensic Stress Disorder" (2001) 25 Law \& Psychol Rev 1, 4-5.

69 Marshall et al, supra note 46 at 292.
} 
conflict; students and families are sharing this experience of fatigue. This gap is even more apparent when one considers the relative silence in the literature about the experiences of overtaxed families, such as those attempting to navigate and triumph in the complexities of special education or English Language Learner programs. In fact, the advice that teachers and school leaders seem to get from peers is to avoid excessive empathy for the most strained of families. One author, for example, warns teachers not to take on emotional burdens by assuming the stresses of parents: "You are not the parent. Teaching happens within a culture of care. Teaching ... is still culturally seen as 'women's work'... However, teachers are not parents to their students." ${ }^{70}$ Teachers and administrators do not exist in a vacuum, particularly where there is conflict. The stressors behind their fatigue are shared and relational, with the other half of that experience between students and families - and ultimately, the reverberations for communities.

In examining the literature surrounding marginalized students and families and the effects of advocacy, several themes emerge: the notion of parental identity and "good" parents and "bad/crazy" parents, ${ }^{71}$ the importance of material resources in effective change strategies, ${ }^{72}$ and the tendency of educational systems to set up families and students to lobby for individual changes versus systemic shifts in policies, practices, and organizational culture. ${ }^{73}$ While the existing literature does not sufficiently focus on the relative experiences of families enmeshed in the special education and bilingual education systems, I will consider how each of these framings might apply to their experiences.

\section{B. Barriers to Advocacy for Parents 1. Good Parents and Bad Parents}

Very little research has been done on how school personnel view parental involvement that includes advocacy for individual students or contested policymaking. This void is remarkable given that schools are generally hierarchical systems tasked with particular instructional and outcome improvement goals, yet also are desirous of "democratic forms of interaction." ${ }^{.74}$ Parents provide unique insights into the experiences of their children and may have different cultural perceptions of the importance - or lack thereof - of language or disability assimilation, for example, that extend beyond seeing their children as having deficits. ${ }^{75}$ Therefore, in conflicts

70 Joanna Krop, Caring Without Tiring: Dealing with Compassion Fatigue Burnout in Teaching, (2013) 52:2 Education Canada 42 at 44; See also Martha Teater \& John Ludgate, Overcoming Compassion Fatigue: A Practical Resilience Workbook, (Eau Claire, WI: PESI Publishing, 2014) at 44 (suggesting that teachers are highly compassionate, but could exercise greater self-preservation by focusing on imparting information rather than tackling children's problems); Mei-Chang, "An Appraisal Perspective of Teacher Burnout: Examining the Emotional Work of Teachers" (2009) 21 Educational Psychology Review 193 at 204, 208 (noting that interactions with parents, particularly around school reform or where their judgment is questioned, enhances teacher anxiety and burnout).

71 Nespor \& Hicks, supra note 3 at 326-327 (describing school administrators' characterizations of parents as "witches," "mediators", and "activists").

72 Sarah D Sparks, "Advocacy Tactics Found to Differ by Families' Class" (2012) 32:2 Education Week 1 at 11.

73 Nespor \& Hicks, supra note 3 at 309-10.

74 Lindy Zaretsky, "Advocacy and Administration: From Conflict to Collaboration" (2004) 42:2 Journal of Educational Administration 270 at 270, 274.

75 Ibid at 278. 
between schools and families, these differences in values play important roles in transforming "parenthood into political parenthood."76 For families of special education students, political parenthood might look like developing a positive disability rights identity within their students by connecting them with peers with disabilities, joining cross-disability organizations, or sharing the message of disability pride through mentoring relationships with adults with disabilities. Similarly, for families of ELL students, the transmission of cultural pride and identity is important and shared by the family itself. Families might strive to preserve the language at home and within their communities, to connect with relatives living abroad, and to transmit stories of significant cultural and historical moments to their children. Both sets of parents must do this work as they confront a public educational system that emphasizes assimilation, homogeneity, and normalization. ${ }^{77}$ Here is the first sense of conflict between home and school. Schools, in operating from a managerial perspective, can often miss the emotional aspect of this transformation process - one that touches on "pain", empathy, pride, fear, anger, and concern. ${ }^{78}$

Camille Wilson Cooper, writing in the context of how schools interpret the involvement of African American mothers, identifies tensions in the rhetoric around schools and parents as "educational partners." ${ }^{, 79}$ While her work does not focus specifically on special education or ELL students, her theories about parental participation raise interesting questions about how families and students from these groups might participate in ways that are not valued by schools the same as able-bodied, white students. She argues that schools tend to appreciate cooperation and obedience over recognizing parents as equal power holders. Additionally, educators struggle with welcoming or sharing power with families that are racial minorities, low-income, or linguistically different, and rather assume that these families have deficits that prevent them from assuming true partnership. ${ }^{80}$ Furthermore, schools can view the advocacy styles of these families from marginalized backgrounds as confrontational, rather than appreciating how ethics around caring might differ based on socioeconomic status. ${ }^{81}$ As Cooper notes, African American mothers often teach their children resilience in the educational system; caring as a parent merges with justice. ${ }^{82}$ Fighting for better educational outcomes in this context means not being silent or nice, and not acquiescing to authority. ${ }^{83}$ White, middle-class approaches to parental participation, such as being classroom volunteers or event organizers, are appreciated over other forms of involvement, such as questioning school leaders' decisions or pointing out acts of

$76 \quad$ Ibid at 272.

77 Roger Slee, "Inclusion or Assimilation? Sociological Explorations of the Foundation of Theories of Special Education" (1997) 11:1 Educational Foundations 55; Howard Phil Parette, "Restrictiveness and Race in Special Education: The Issue of Cultural Reciprocity" (2005) 3:1 Learning Disabilities: A Contemporary Journal 17; Youb Kim \& Patricia H Hinchey, Educating English Language Learners in an Inclusive Environment (Peter Lang Publishing Inc, 2013).

78 Zaretsky, supra note 74 at 275.

79 Camille Wilson Cooper, "Parent Involvement: African American Mothers and the Politics of Educational Care" (2009) 42:4 Equity \& Excellence in Education 379 at 380.

80 Ibid.

$81 \quad$ Ibid at 382 .

82 Ibid at 384.

83 Ibid. 
discrimination in the education system. ${ }^{84}$ This dynamic is reinforced when school staff are ethnically or racially homogenous. Unfortunately, any strained relationships between the school and parents can translate into further marginalization of students already undervalued because of their differences. ${ }^{85}$

Parents advocating for children with disabilities or English Language learners can become "good" or "bad" based on their submission to the dominance of professional vocabularies and technical expertise around assessment, treatment, and interventions, for example. ${ }^{86}$ Openly challenging such authority leads these parents to be characterized as angry or crazy. ${ }^{87}$ In the context of special education, Nespor and Hicks argue that some parents are uncomfortable with this role and choose to position themselves as mediators that bridge the tensions between administrators and families. ${ }^{88}$ In this capacity, parents turn from being fierce advocates to trying to find common ground between schools and families, but they do so from a subordinate position where they are expected to acquiesce to professional expertise and administrative power to make small steps forward with educational equity. Their original advocacy goals can become diluted and even extinguished.

\section{Material Resources and Effective Advocacy}

Beyond being perceived as helpful or harmful to their students' progress and schools' goals, parents are also constrained and influenced by tangible limitations on their material resources. Time and money are the most obvious of those limitations; yet, parents cannot "outsource" this work to achieve the goals that most resonate with them. For example, in studying the kinds of advocacy done by civil rights organizations compared with parents and parent groups during the desegregation of public schools, sociologist Melissa Weiner found that parents had concrete goals that involved improving curriculum and the daily environment of schools, whereas civil rights organizations advanced abstract ideals of equality and integration. ${ }^{89}$ Parents play important roles in not only getting the work of school improvement done, but in also modeling advocacy for their children. ${ }^{90}$ I will return to this potential role of parents in the final section of the paper.

Many parents will not have the time or energy - particularly if they are already embedded in conflict with the school - to participate in the everyday happenings of their child's classroom. Lack of "school-site involvement" further distances the school-family relationship. ${ }^{91}$ However, effective advocacy is time-consuming and does not leave a lot of space for volunteerism or PTA leadership. ${ }^{92}$ Parent-advocates must learn the language of education and then apply it to begin to be effective at changing conditions for their students in special education or bilingual language

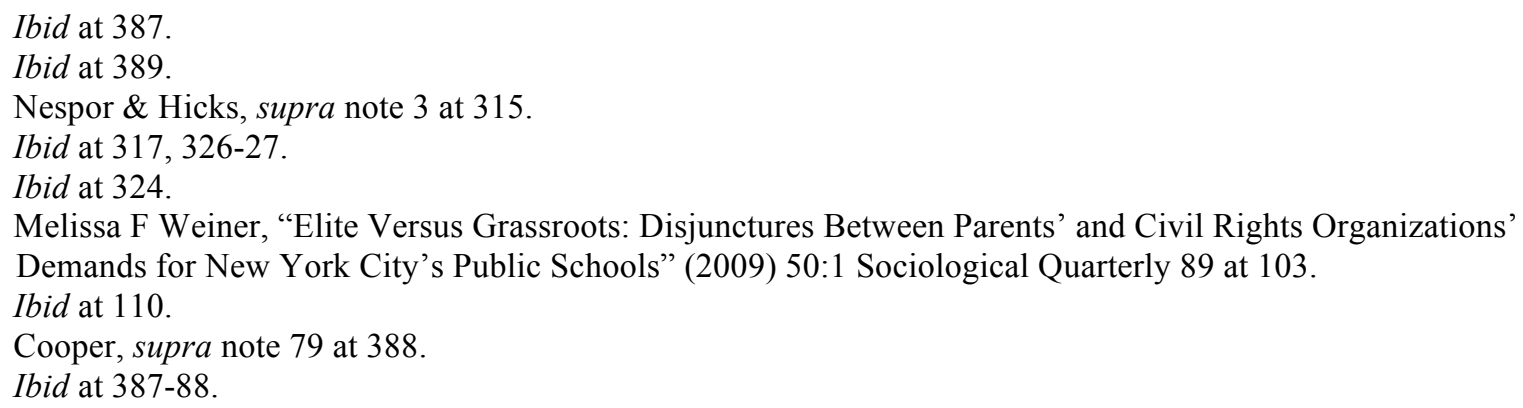


learner programs. ${ }^{93}$ Having a flexible work schedule or being able to afford making advocacy for one's student as the primary job helps, but it is not a curative. ${ }^{94}$ Most solutions to student issues, when generated, tend to be ephemeral and elusive; they need to be revisited sometimes classroom by classroom, grade year by grade year. ${ }^{95}$

Furthermore, effective advocacy is constrained by class, particularly where parents must suggest alternative educational strategies for their children or bring in experts to contest placement decisions. ${ }^{96}$ However, class can also operate as a barometer for how parents advocate, and in turn, model that behavior for their children. ${ }^{97}$ For example, a recent study demonstrated that working-class parents raised their children to be "self-sufficient" and "to avoid conflict," while middle-class parents emphasized self-advocacy skills with their children. ${ }^{98}$ These kinds of studies need to be replicated with sensitivity to race, ethnicity, language, and disability status and their intersections. One approach to advocacy is not necessarily better than another-they were simply different strategies to similar problems. While the populations of parents of ELL and special education students are not homogenous in terms of class, race, and ethnicity, they are more likely than parents of non-disabled students or English-as-a-primary-language students to experience structural disadvantages that have economic impacts, such as immigration status, language access barriers, the costs of educational or medical interventions, and the weight of assessment and diagnosis.

Nespor and Hicks note that limitations affect parents who are well-educated and affluent, as well. ${ }^{99}$ Even though they might be better prepared to understand and respond to the professional vocabulary of schools and to bring in outside assessments and professionals, these families still experience strains in leveraging these resources: "In all cases, the time required and expenses entailed in caring for the children and contending with schools taxed and exhausted all parents." interactions with schools. ${ }^{101}$

\section{Individual vs. Systemic Vision}

While families might share this experience of exhaustion in the system, the kinds of advocacy required for marginalized students, such as ELL and special education students focuses, for the most part, on individual plans and outcomes, such as specialized instruction or language transition strategies. ${ }^{102}$ Given the constraints just explored, parents-even where they are so

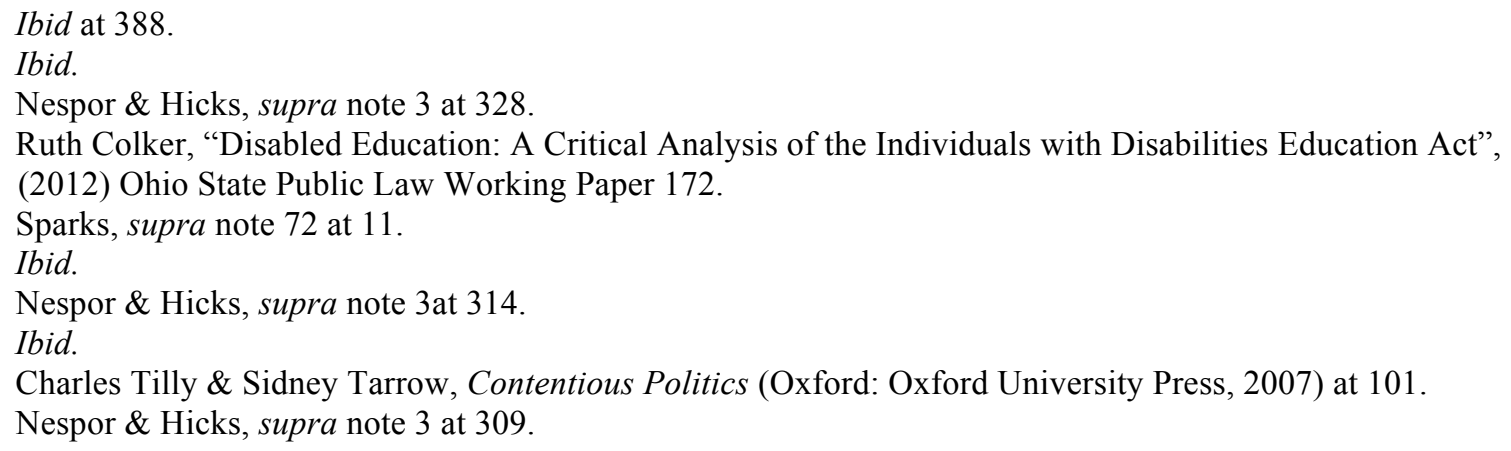


inclined toward collective action-might simply not be able to sustain it. ${ }^{103}$ If all parents engaged in advocacy are policymakers, as suggested earlier, then this kind of network of policymaking is one of distributed rights and sometimes disparate goals. ${ }^{104}$ At the extreme, seeing change for one's own student can take on the flavor of fierce individualism. Such individualism can be a tool to challenge homogenized decisions about the "group" to which the student belongs, such as all ELL students or all children in special education or with particular kinds of disabilities. ${ }^{105}$ Rallying around choice and individuation can emphasize the importance of tailored and nuanced approaches to education.

However, both principals and parents recognize the need for systemic change-where individual stories are not lost in broader advocacy and vice versa. ${ }^{106}$ Several studies, focused specifically on special education, have demonstrated that when parents are successful at advocating for their children, they are then more likely to join collective efforts to reform education and to support other parents later. ${ }^{107}$ However, as Zaretsky posits, perhaps, the parents' original conflict stemmed from not having a collective orientation from the beginning where they would have benefited from the support of others and the wisdom of their experiences. ${ }^{108}$ But as Cooper suggests, these conceptualizations of how parents orient themselves toward educational equity, might not capture the full array of experiences or perspectives - such as Black women's "resistance and collective uplift goals" and some minority parents' perspectives of dissent as being important in ensuring democratic school cultures. ${ }^{109}$ These lessons are critical ones to consider as we attempt to define both the problem and reconceptualize how to address it within different communities.

\section{DEFINING ADVOCACY FATIGUE}

If parents "do not operate with equal access, knowledge, resources or power in educational systems" 110 and they may display care and concern in myriad ways, then how can schools and policymakers best begin to ask questions about, and capture the experiences of families engaged in often contested relationships with schools? How might this shift in perspective be critically informed by differences in how families and schools see the students that become the sources of the "problems", the locus of the conflict? In this section of the Article, I argue for a reconceptualization of care, compassion, and fatigue, and attempt to capture it with the term "advocacy fatigue."

\footnotetext{
103 Nespor \& Hicks, supra note 3 at 310.

104 Ibid at 311.

105 Zaretsky, supra note 74 at 272.

106 Ibid at 276-77.

107 See Maya Kalyanpur \& Beth Harry, Culture in Special Education: Building Reciprocal Family-Professional Relationships (Paul H Brookes Publishing Corporation, 1999); Carol Vincent, Including Parents: Education, Citizenship and Parental Agency (Open University Press, 2000).

108 Zaretsky, supra note 74 at 277.

109 Cooper, supra note 79 at 385, 390.

110 Ibid at 390.
} 


\section{A. Merging the Professional Fatigue Literature with Parent Advocacy Research}

Thus far, I have discussed forms of fatigue and conflict fallout that affect professionals and parents, but have done so from their individual perspectives. Furthermore, the literature's focus on the negative effects of interacting with families reinforces ideas of parent advocates on the margins, and students themselves, as troublesome, antagonistic, irrational, or at best-dependent. In this section, I plan to merge the two literatures to present some core features of what will become my working definition of "advocacy fatigue." These three core features are care as power, the relational nature of identity, and the primacy of the advocacy role in the face of diminished social supports.

First, both the discussions of parent and professional perspectives underscore the intertwined nature of caring and power. ${ }^{11}$ Caring is not simply something that someone with authority does altruistically; caring, like power, is mutual. It "benefits both parties" but is not "linear.",112 Caring brings a sense of "moral authority", too, that can be transformative in education. ${ }^{113}$ Therefore, any approach to capture the mental, physical, and social effects of marginalized parents engaged in advocacy must include the politics of care at its core - and the recognition that sometimes care looks like individual nurturance, and other times, it resembles political protest and resistance. ${ }^{114}$

Secondly-building on the relational element of caring-both parental and professional identities are tied to the relationships and interactions that each has with children. ${ }^{115} \mathrm{We}$ desperately need greater studies in the education and sociology literature about how families and teachers care about students in similar and different ways and how those dynamics shape their own potential for collaboration and conflict. Caring means that someone, whether a parent or a teacher, can take on the pain and the social status of the marginalized student. This is how teachers come to experience burnout when they are ineffective in realizing social justice in their schools. ${ }^{116}$ And this is how parents' own socioeconomic marginalization can be further compounded by the actual struggles of their children and society's biased and stereotypical

111 See Nel Noddings, Educating Moral People: A Caring Alternative to Character Education (Teachers College Press, 2002); Angela Valenzuela, Subtractive Schooling: US-Mexican Youth and the Politics of Caring (Albany: State University of New York Press, 1999).

112 George Noblit, "Power and Caring" (1993) 30:1 American Educational Research J 23 at 35.

113 Ibid at 37.

114 Cooper, supra note 79 at 385.

115 See generally Sheldon Stryker \& Peter J Burke, "The Past, Present, and Future of an Identity Theory" (2000) 63:4 Social Psychology Quarterly 284 at 284.

116 See e.g., Barbara C Gartin et al, "Issues and Challenges Facing Educators Who Advocate for Students with Disabilities" (2002) 37:1 Education \& Training in Mental Retardation and Developmental Disabilities 3 at 12 (discussing the role conflict caused when teachers need to advocate for students with disabilities); Shari Hoffman, John Palladino \& Jeffery Barnett, "Compassion Fatigue as a Theoretical Framework to Help Understand Burnout Among Special Education Teachers" (2007) 2:1 Journal of Ethnographic \& Qualitative Research 15 at 16-17 (arguing that the elements of compassion fatigue are particularly high among special educators); Jennifer Miller, “Teachers' Work in Culturally and Linguistically Diverse Schools" (2011) 17:4 Teachers \& Teaching 451 at 452 (identifying the need for more research about the struggles of teachers working in linguistically diverse and low socio-economic schools). 
perceptions of them. ${ }^{117}$ These biases trickle into how teachers and administrators view families and students, as well, further compounding marginalization in a space that should be one of student advancement and development.

We know from the literature on educational professionals' experiences of conflict that it is multi-dimensional and can be exacerbated or alleviated by structural supports, such as a sense of community, reduced exposure to trauma, and clarification of roles and contributions. ${ }^{118}$ Conflict can take both an emotional and physical toll. Mental health professionals advise others employed in care-giving fields to gain distance from the work to allow time for processing trauma and recognizing a semblance of balance. ${ }^{119}$ However, this kind of distancing, as difficult as it is for principals and teachers, is nearly impossible for parents. They are in the thick of it because they are often the only or the best ones to assume this role. ${ }^{120}$ While in this dynamicwhich might be short-term or last the duration of their children's schooling-families confront limited resources of time, energy, and money, and must choose among obligations, with advocacy for their students being one of those choices.

\section{B. Advocacy Fatigue: Relational and Structural}

I define advocacy fatigue as the increased strain on emotional, physical, material, social, and wellness resources that comes from continued exposure to system inequities and inequalities and the need to advocate for the preservation and advancement of one's rights and autonomy. Advocacy fatigue can diminish emotional and physical health, career prospects, and financial security because of the ongoing exposure to stress and discrimination. It can cause students, families, and communities to "burnout" on school; school and its administrators and teachers become adversaries in the process rather than collaborators. While I have provided a working definition, I do not assume that advocacy fatigue is a universal experience. I would expect that its form and effects vary from family to family and are not homogenous among families even with shared marginalization experiences. By elaborating on advocacy fatigue, I am shifting the attention from professionals back to the others most precarious in conflicts and highlighting the importance of considering race, language, ethnicity, and ability - among other factors - in the experience of fatigue and the provision of support mechanisms.

This definition shifts the perspective from the psychological and physical toll of conflict on teachers and principals, or the advocacy styles and constraints of parents, to an appreciation for

117 See e.g., Rachel C Berman \& Leslie Wilson, "Pathologizing or Validating: Intake Workers' Discursive Constructions of Mothers"(2009) 19:4 Qualitative Health Research 444 at 451-52 (describing the ways in which mothers of children with disabilities take on the biases of their children's disabilities and are pathologized or supported by health care workers); Esther Ntuli, Arnold Nyarambi \& Moussa Traore, "Assessment in Early Childhood Education: Threats and Challenges to Effective Assessment of Immigrant Children" (2014) 14:4 J Research in Special Educational Needs 221 at 224 (identifying the bias associated with the label of "ELL" and its effects on parents and students).

118 See discussion below at section IV.

119 Maltzman, supra note 42 at 315.

120 See Lori A Roscoe, H Osman \& W E Haley, "Implications of the Schiavo Case for Understanding Family Caregiving Issues at the End of Life" (2006) 30:2 Death Studies 149 at 151 (describing caregiving as a "long and extended career"). 
the consuming and vulnerable experience of parents as they advocate for educational change. This approach recognizes that parents share in the traumas of their students and that such emotional investment results in family stress and changed dynamics that touch everyone from siblings ${ }^{121}$ to coworkers. At the same time, the world of advocacy is not purely internal and emotional in its obstacles and effects. Structural barriers, such as the need for legal sophistication and literacy, compound the emotional stakes of caring. ${ }^{122}$

"Advocacy fatigue", in joining both the socio-legal and the psychosocial, also places community at the core of analysis. Here, "community" is inclusive of schools, not merely in opposition to them, because one of the primary relationships that parents have through their children is with schools. As Richard Arum has argued, while this focus on how the adults are getting along is important, it must also be inclusive of how students are relating to their teachers and administrators to see significant student progress. ${ }^{123}$ Furthermore, these relationships are ongoing and need to be as functional as possible to minimize the daily stressors in students' lives. Sometimes, this relationship because of contention or missed opportunities for communication and collaboration will become a source of overwhelming stress. In this situation, parents and students best know their individual circumstances and schools best know what their school does-yet, that does not forestall the opportunity to be creative in fashioning new policies and practices.

Advocacy can be overwhelming because of the tensions between individual vision and outcomes and larger desires for educational reform. ${ }^{124}$ Even though many parents might simply want their own children's school days to improve, they might observe greater social problems that need attention, and feel pressure from other families or internal guilt to spring forward reforms for the collective in rallying for their particular student. ${ }^{125}$ They enter into these roles largely without experience as lawyers, community advocates, mediators, or policymakers. ${ }^{126}$ The learning curve is steep. The sophistication required to speak the language of education is palpable. The stakes, for one's individual child, or a group of children, are high. There is no walking away at the end of the day or compartmentalizing stress for the goal of wellness outside "work." Home and work merge in highly politicized ways. ${ }^{127}$

121 Mamta Saxena \& Kari Adamsons, "Siblings of Individuals with Disabilities: Reframing the Literature Through a Bioecological Lens" (2013) 5:4 J Family Theory \& Rev 300 at 301 (noting that siblings of children with developmental disabilities are "more likely to come from a single-parent home (having a child with disabilities stresses marriage); to have had at least one parent working reduced hours or bring unemployed (often the mother to care for the child with disabilities), and thus to have grown up with both lower household income and higher bills accumulated in caring for the needs of the child with disabilities; and to have had parents whose own health was adversely affected by the stress of caring for the child ...").

122 See generally David Schimmel, Parents, Schools, and the Law (National Committee for Citizens in Education, 1987) (outlining areas of basic legal literacy for parents).

123 Richard Arum, "Improve Relationships to Improve Student Performance" (2011) 93:2 Phi Delta Kappan 8 at 9.

124 Nespor \& Hicks, supra note 3 at 309-10.

125 Ibid at 324.

126 Maya Kalyanpur, Beth Harry \& Tom Skrtic, "Equity and Advocacy Expectations of Culturally Diverse Families' Participation in Special Education" (2000) 47:2 Intl J Disability, Development, \& Education 119 at 120.

127 Zaretsky, supra note 74 at 272. 
Whether in the arena of policymaking or litigation, such advocacy will meet with constant and long-standing barriers to breaking through institutional practices. ${ }^{128}$ As Kalyanpur, Harry, and Skrtic, writing in the field of special education, have described, the tension in education is between institution and innovation, but there are also issues of shared values and questions of comfort with challenging authority. ${ }^{129}$ Policy-making efforts, therefore, will confront the primacy of professional knowledge and the vocabularies surrounding it. ${ }^{130}$ Such a hierarchy often incorporates a deficit-based approach to viewing marginalized parents. ${ }^{131}$ Additionally, parents might encounter professionals struggling to manage their own descent into compassion fatigue and burnout, in which they cannot fathom taking on an additional conflict or disappointment. The reaction, therefore, that families get from even the most empathic school leaders might be one of resistance or avoidance.

If conflict escalates to legal action, then families will have to represent themselves or spend funds on expensive education lawyers. In this process, both parents of children in special education and ELL programs have shared legal protections that trigger a process of complaint, rights enforcement, and conflict resolution that is increasingly sophisticated at each step. Even the process of filing a lawsuit or requesting a due process hearing is daunting with assistance. ${ }^{132}$ Without such guidance, it is overwhelming - and many parents will choose to drop out of the conflict rather than move forward. ${ }^{133}$ In doing so, they might be exercising a sense of selfpreservation, as informal conflicts become formalized in the legal system, and take many years to resolve. This resolution is often mixed; parents might "win" a case only to have a student who has not been served for years and has fallen dangerously behind or has developed an oppositional relationship to school. ${ }^{134}$ Very few community resources exist to bolster families in the process. Even fewer are available to lower-income or Limited English Proficient families who might require translation and interpretation to begin to make sense of the system. ${ }^{135}$ The end result is that families with material resources or legal sophistication are more likely to push for rights enforcement through the administrative law process. While no robust literature exists on this issue, I would postulate that those families are more likely to be upper middle class or wealthy parents of children with disabilities rather than families in the ELL system.

If advocacy is viewed as a spectrum, extending from an initial informal conflict to a trial in court and the rendering of a decision (and perhaps, an appeal of that decision), then we can see

128 Kalyanpur et al, supra note 126 at 120.

129 Ibid.

130 Ibid.

131 Zaretsky, supra note 74 at 278.

132 See discussion above re: litigation stress.

133 See generally William L F Felstiner, Richard L Abel \& Austin Sarat, "The Emergence and Transformation of Disputes: Naming, Blaming, Claiming ”(1980-1981) 15:3/4 L \& Soc'y Rev 631 (describing the transformation of disputes from informal to formal and the experiences of the parties engaged in conflict).

134 Branda L Nowell \& Deborah A Salem, "The Impact of Special Education Mediation on Parent-School Relationships: Parents' Perspective" (2007) 28:5 Remedial \& Special Education 304 at 308 (showing mediation does not necessarily increase positive relationships at school post-resolution, but rather decreases negative interactions).

135 Kalyanpur et al, supra note 126 at 124-25. 
the multiple junctures where families can fall out of the fight. This is a game of attrition. ${ }^{136}$ In general, families, particularly with ELL students and special education students, are underpowered in resources for conflict-legal or otherwise-when compared to school systems. ${ }^{137}$ The emotional toll of the conflict permeates family interactions. ${ }^{138}$ It becomes the other family member at dinner, the hushed conversations after children's bedtimes, the reduced work hours to make school meetings, the impromptu requests for friends to serve as interpreters and translators.

The farther along the conflict gets in being formalized, the longer it lasts in many cases. The family can end it, but at what daily cost? They must still have a plan for educating their child, such as transferring schools or paying for private school-where any of these issues could arise again. They can resign themselves to educational inequity. They can attempt to work the political process by bringing in politicians, the media, advocacy organizations, or other stakeholders to apply pressure or to broker conciliations. All of these avenues are exhausting and alienating, for the most part. In pursuing them, families' relationship to school-both as a local and abstract institution-alters.

\section{STRATEGIES FOR ADDRESSING ADVOCACY FATIGUE}

\section{A. Why Haven't We Talked About It?}

The description of advocacy fatigue might seem obvious but it is not explored robustly in the literature. Why have our perspectives been so myopic in either focusing on professionals' experiences of burnout or parents' advocacy styles and structural barriers? Before outlining some strategies for improving schools and policy practices that address advocacy fatigue and its causes, I will suggest some reasons for why there has been so little theorizing about advocacy's multi-faceted toll on families, particularly in the marginalized groups of parents of children in special education or ELL programs.

While parents stand in the shoes of their children in advocating for educational rights, schools operate under "in loco parentis", the Latin for "in the place of a parent." "139 In doing so, schools are vested to act in the best interests of the child as they see fit. However, this role can take on one of paternalism, as schools begin to act with authority on behalf of particularly vulnerable parents or students. ${ }^{140}$

136 Ronald J. Gilson \& Robert H. Mnookin, "Disputing Through Agents: Cooperation and Conflict Between Lawyers in Litigation" (1994) 94:2 Colum L Rev 509 at 512 (describing the "prisoner's dilemma" of litigants).

137 Lauren B Edelman \& Mark C. Suchman, "When the "Haves" Hold Court: Speculations on the Organizational Internalization of Law" (1999) 33 L \& Soc'y Rev 941 at 941 (recognizing that the legal system privileges repeat, institutional players).

138 Nowell \& Salem, supra note 134 at 310, 313 (suggesting future research in the impact of educational conflict on parents' sense of efficacy).

139 Legal Information Institute, "In Loco Parentis", online: Cornell University Law School <http://www.law.cornell.edu/wex/in_loco_parentis>.

140 See Judith L Pace \& Annette Hemmings, "Understanding Authority in Classrooms: A Review of Theory, Ideology, and Research" (2007) 77:1 Rev Educational Research 4 at 21-22 (discussing critiques of hierarchical approaches to authority). 
Such paternalism can distance school leaders from the lived realities of families. These families and students, because of their disabilities or language differences, become objects and not subjects. This objectification is not a natural result of the care dynamic of schools. Rather, it is a distortion of the dedication to professional training and power in the school-family dynamic. This kind of distortion can be intentional - such as if school leaders and teachers view themselves as having the clearest or best interests for the student-or subconscious - such as where teachers and principals are protecting themselves from further effects of compassion fatigue and burnout by either becoming directive or distant in managing the school-family conflict.

At the heart of these conflicts, and perhaps tied to the under-exploration of the effects of advocacy on families, are assumptions within professional training and the educational system itself about shared values for the goals of education, the development of children, concepts of equity, and ideals of democracy. However, as Kalyanpur, Harry, and Skrtic elucidate, this assumption is dangerous. ${ }^{141}$ Families, because of their varied backgrounds and experiences that are rooted in class, culture, race, ethnicity, and national origin approach education and confrontation differently. ${ }^{142}$ They might, for example, not understand or not be comfortable with challenging educators' assessments of their children or asserting choices of their own. ${ }^{143}$ They might view educators' observations about their child's weaknesses or strengths as additional negative judgments about their cultural differences or language deficiencies. ${ }^{144}$ Furthermore, rather than having a distinctively "American" approach to rights and identity, families from different cultural backgrounds might emphasize group outcomes over individual organizing. ${ }^{145}$ Therefore, the assumption that we all believe in the same notion of education or equity, or that we all protest in the same way, deepens conflicts and leads to ineffective conversations.

One of the fundamental areas of such values conflict is over what disability or language differences mean - and whether those are deficits to be pathologized and fixed, or to be celebrated and accommodated for by schools. ${ }^{146}$ Indeed, this is where the fields of disability studies and multicultural education have much to offer these interactions and school personnel because they challenge the idea that access needs, whether posed by disability or language, equate to problems. Research in multicultural education suggests that English Language Learners receive diminished instruction because of the "hidden curriculum" of education that assumes that non-English-speaking students have far less to offer than native speakers. ${ }^{147}$ Disability studies, in particular, through its focus on the collective social struggle of people with

141 Kalyanpur et al, supra note 126 at 120.

142 Ibid.

143 Ibid at 121-22.

144 Ibid at 124.

145 Ibid at 127-28.

146 Ibid at 124.

147 Christopher T Vang, "Minority Parents Should Know More about School Culture and Its Impact on Their Children's Education" (2006) 14:1 Multicultural Education 20 at 20. 
disabilities and the structural barriers that they face, would suggest that the appropriate response to such differences is pride and the development of self-esteem and community. ${ }^{148}$

As Zaretsky notes in the field of special education, "when parents advocate for children with exceptionalities they often challenge deep-seated beliefs about disability and special education" that lead to "confrontational and conflicted" interactions with schools. ${ }^{149}$ Parents, even more so than school leaders, can be concerned about the social barriers that limit their children more than the functional or diagnosable ones identified by educators. ${ }^{150}$ For example, schools and families might experience fundamental disconnects over what problems students are experiencing if schools perpetuate the stigmatizing viewpoint that students' differences, whether language or disability, are bad-and families view the real problem as one of social exclusion and devaluation. If a school, for example, worries about a student's lack of progress in mastering English, a family might worry that the school has pushed too hard for the student to lose her native language. Similarly, a family might attend an Individualized Education Program [IEP] meeting wanting to know why a student with dyslexia has spent so much time in the selfcontained classroom and now feels excluded socially from mainstream school activities, while a school might stick to a narrative of reading scores and percentiles that do not capture the student's efforts to learn nor the limiting effects of stigmatizing his disability. Stigma permeates the interactions that parents have with schools-and therefore, distances schools from understanding their emotional experiences of discrimination-because they come to stand in the shoes of their marginalized children, even if they, themselves, do not share the same limitations. Stigma by association can be almost as powerful as being the primary bearer of discrimination and stigma. ${ }^{151}$

Erving Goffman, writing about stigma in the 1960s, suggested that stigma can be transferable - where someone related to or affiliated to the person with the original mark of difference, such as speaking another language or having a physical or mental disability, becomes discriminated against, as well. ${ }^{152}$ This stigma might take the form of negative reactions alone, or

148 See Sharon Barnartt, "Disability Culture or Disability Consciousness?” (1996) 7:2 J Disability Policy Studies 1 (arguing that disability culture is best reframed as the development of disability consciousness); Clare Connors \& Kirsten Stalker, "Children's Experiences of Disability: Pointers to a Social Model of Childhood Disability" (2007) 22:1 Disability \& Society 19 (suggesting that most children with disabilities need and lack a positive narrative of their disabilities).

149 Zaretsky et al, supra note 74 at 272.

150 Ibid at 279.

151 Margareta Ostman \& Lars Kjellin, "Stigma by Association: Psychological Factors in Relatives of People with Mental Illness" (2002) 181 British J Psychiatry 494; Stacey Hannem \& Chris Bruckert, Stigma Revisited: Implications of the Mark (Ottawa: University of Ottawa Press, 2012) at 96-98.

152 Erving Goffman, Stigma: Notes on the Management of Spoiled Identity (New York: Simon and Schuster, 1963) at 43, 153; See also Joyce Turner et al, "Parenting Children with Proteus Syndrome: Experiences with, and Adaptation to, Courtesy Stigma” (2007) 143A:18 American Journal of Medical Genetics Part A 2089 (discussing coping strategies that parents use in responding to courtesy stigma based on having a child with genetic differences; Mirka Koro-Ljunberg \& Regina Bussing, "The Management of Courtesy Stigma in the Lives of Families with Teenagers with ADHD” (2009) 30:9 J Family Issues 1175 (finding that courtesy stigma heightens the responsibility and stresses of families); David E Gray, "Perceptions of Stigma: The Parents of 
it can also incorporate the expectation that the affiliated person — the parent, here- is "wise" and offers insights into how to best assist the "afflicted individual." 153 Parents, therefore, are thrust into roles where they have multiple, high-stakes responsibilities, all of which revolve around mitigating the other person's differences - or being further outcast themselves. ${ }^{154}$ This "courtesy stigma" is underexplored in the educational or sociological literature, yet its effects might be influencing families' experiences of advocacy fatigue and schools' reactions to them. ${ }^{155}$ Parents advocating for ELL students or special education students might bear both primary stigma and courtesy stigma, compounding the strains on their resources to fight discrimination or to achieve equity in schools.

\section{B. What Can We Do?}

In recognizing advocacy fatigue as a lived experience that affects families' relationships with schools, we must also consider what reform stemming from this understanding might look like. I do not suggest in any way that there is a simple response to a complex problem, but I would like to draw from the existing literature to offer some strategies for improving the school-family relationship, and in turn, outcomes for ELL and special education students, among other marginalized populations. These suggestions take three primary forms: professional training, facilitated communication, and community collaboration.

\section{Professional (Re)Training}

One advantage of the burgeoning literature on compassion fatigue and burnout in the context of education is the implications that it can have for better integrating concepts of the whole teacher or whole principal into school values, supports, and training. Recognizing the concomitant experiences of fatigue and burnout for families is the next step. Professional development strategies should include developing sensitivity to recognizing one's own limitations as a professional and identifying and enhancing sources of support to avoid burnout, but also gathering resources for families and students. Opening these conversations about struggles that marginalized families have helps professionals to shift perspectives from inside of themselves and to recognize, collectively, the realities of educational equity, rather than seeing specialized services as an "out of control monster" or parent advocates as the same. A potential approach to addressing these issues of inclusive empathy is to ensure that discussions about values (e.g., culture, identity, disability, language) are at the core of every professional development exercise that has an ELL or special education focus. Too often, the emphasis in professional development and the implementation of those trainings is merely on procedural compliance. ${ }^{156}$ However, we recognize that teachers and principals might approach even the

Autistic Children" 15:1 Sociology of Health \& Illness 102 (exploring courtesy stigma in families with autistic children and the management of stigmatized identity).

153 Gray, supra note 152 at 104.

154 Ibid.

155 Hannem \& Bruckert, supra note 151 at 97.

156 See e.g., Sara Lipka \& Brad Wolverton, "Title IX Enforcement Called 'Deeply Troubling”" (2007) 53:43 Chronicle of Higher Education A1 at A1 (emphasizing the focus on legal and procedural compliance, as compared to substantive change, in higher education equity issues, for example). 
most basic understanding of language and cultural differences, as well as disabilities, in profoundly different ways from families. ${ }^{157}$ Incorporating training on implicit biases is critical and its effects in the field of education are missing from the existing literature. ${ }^{158}$ This kind of training can include people from these experiences and perspectives, and might be most effective if they include professionals from these backgrounds. In this way, educators can begin to bridge the divide between their professional knowledge hierarchy and the lived wisdom of families and students from diverse backgrounds. Ultimately, diversity and empathy must be recognized in hiring teachers, principals, and support staff that better represent the populations served through their own identities and experiences. ${ }^{159}$

\section{Facilitated Communication}

While some scholars have emphasized that one potential solution to the contentious divides that arise between families and students is more communication, I would contend that it is better communication. ${ }^{160}$ Conflicts are not often silent ones. Rather, they might be marked by miscommunication or misinformation, discussions around difficult and sensitive topics, or assumptions on both sides about what the other really wants. ${ }^{161}$ Given the formalistic processes inherent to special education and language access programs, schools and families stand to benefit tremendously by making thoughtful, informal, and frequent communication a goal before conflict arises.

Parents and schools can facilitate better communication by making discussions of values and vision part of every conversation. ${ }^{162}$ Some of these questions might look like: Why and how is disability an important part of the family's experience and the student's identity, both positively and negatively? What is the family doing to preserve the student's native language and how does a curriculum with English as the focus threaten or assist those efforts? What does the teacher or principal want to know more about, as they work to put together services? What are they worried they have misunderstood? In broaching these sensitive topics and seeking common ground, both schools and families shift from worrying about merely procedural compliance with education law to brainstorming about substantive improvements to delivery,

157 Kalyanpur et al, supra note 126 at 120.

158 Ibid.

159 Sonia Nieto, Sonie Felix \& Karen Gelzinis, “A Life of Teaching: Reflections from Teachers in an Inquiry Group" (2002) 1:2 Perspectives on Urban Education, online: Penn Graduate School of Education

$<$ http://www.urbanedjournal.org/archive/volume-1-issue-2-fall-2002/life-teaching-reflections-teachers-inquirygroup $>$.

160 Archerd, supra note 18 at 401.

161 Lavine, supra note 5.

162 See generally Susan Florio-Ruane \& Julie deTar, Teacher Education and the Cultural Imagination: Autobiography, Conversation, and Narrative (Mahwah, NJ: Laurence Erlbaum Associates, 2001) (bringing together the tools of autobiography and conversation to approach difficult conversations in education); Michelle Garcia, Take the Initiative, (2009) 36 Teaching Tolerance, online: Teaching Tolerance

$<$ http://www.tolerance.org/magazine/number-36-fall-2009/feature/take-initiative > (suggesting that diversity training alone is not enough and that teachers must be supported in taking steps toward open communication that addresses the achievement gap). 
resource limitations, and long-term outcomes. ${ }^{163}$ These conversations are difficult and might require some outside facilitation by community groups, parent advocates or PTA leaders, other professionals helping with the child's education or health, and district leadership.

In situations where conflicts become more formal and are heading toward court, both families and schools could benefit tremendously from having their disputes mediated by professionals with better understandings themselves about cultural differences and access issues as forms of equity. Mediation, therefore, would encompass the provision of accommodations and appropriate, meaningful language translation and interpretation. ${ }^{164}$ However, mediation is not an elixir, a repair for relationships that have become damaged over time. ${ }^{165}$ Rather, the overarching goal should be to give schools and families the tools to better communicate on a daily basis, if needed, and to resolve conflicts before they take further tolls on limited resources on both sides. In litigation, resource-strapped parents are only further disadvantaged, while middle class and wealthy parents can "lawyer up" to achieve better outcomes for their children. ${ }^{166}$

\section{Community Collaboration}

Thus far, notions about community advocacy for vulnerable students take on the shape of impact litigation, rather than leveraging the community as a central stakeholder in collective change. ${ }^{167}$ Fully realizing the vision of democratic approaches to education, such as those embedded in the Individuals with Disabilities in Education Act, for example, ${ }^{168}$ will require making parents equal partners in collaboration. This change can happen through shared governance, respect for parent input and knowledge, and consciousness-raising among parents and communities.

Shared governance entails placing parents in key decision-making roles in daily school practices, rather than just in moments of crisis. Thus far, shared governance has looked more like "mutual responsibility for decision-making" that has brought a "higher degree of expressed disagreement and conflict" because it lacks the improvements in training and communication first. ${ }^{169}$ Skrtic, for example, has argued for "critical pragmatism" as one strategy toward achieving shared governance. ${ }^{170}$ Here, educational professionals approach their decision-making power and sense of what is right with some skepticism and turn to parents to teach them about the gaps. Part of this shift comes with recognizing the ways in which parents sometimes seen as controversial or combative figures are demonstrating care in different ways and might be attempting to teach their children the importance of resilience and protest. ${ }^{171}$

\footnotetext{
163 Kalyanpur et al, supra note 126 at 131.

164 Archerd, supra note 18 at 400.

165 Nowell \& Salem, supra note 134 at 308.

166 Colker, supra note 96.

167 Archerd, supra note 18 at 401.

168 Kalyanpur et al, supra note 126 at 119

169 Nowell \& Salem, supra note 134 at 304.

170 Tom M Skrtic, "The Special Education Knowledge Tradition: Crisis and Opportunity” in E L Meyen \& T M Skrtic, eds, Special Education and Student Disability: An Introduction to Traditional, Emerging, and Alternative Perspectives $4^{\text {th }}$ ed (Denver: Love Publishing, 1995)(4th ed.) 567-608.

171 Cooper, supra note 79 at 382, 390.
} 
Rather than expecting that parents know their rights and know the professional language of education, schools can shift their values to seeing parents as fonts of valuable knowledge about individual student and shared community experiences. ${ }^{172}$ Parental information can be pivotal, for example, in evaluating students' needs, yet it often takes a backseat to formalized assessments and diagnostic tools.

Schools enter these conversations expecting that families will contest troublesome characterizations, but this reliance on the exercise of rights equally by all parents is misplaced. ${ }^{173}$ Parents with competing stressors might be further disadvantaged in receiving the informal knowledge about navigating schools' policies and practices that comes from parent networks. ${ }^{174}$ Schools need to be proactive in changing this paradigm by placing parents in expert roles - with community support and encouragement-rather than waiting for parents to wrest power from schools. ${ }^{175}$

For families, community groups and collaborative strategies can serve to both raise consciousness among parents about educational equity issues and mobilize a unified voice around shared concerns. As most parents will not be able to outsource their advocacy fatigue, the next best solution is finding both a social and emotional support network that has technical knowledge about increasing the quality of communication with schools, improving parent efficacy in advocacy, ${ }^{176}$ and reaching consensus. Community groups and networks of parents across schools can assist families in communicating how their students have become "the sum experience" of a number of socioeconomic disadvantages - and relay how school has played its part and can change the course. ${ }^{177}$ Community groups might also be robust sources of cultural education and communication support for schools - such as providing interpretation and translation services in diverse communities, training parent peer support advocates to take notes and ask questions at school meetings, and helping schools understand the burdens and opportunities of cultural brokering that ELL students experience. In the disability context, community groups can offer support to schools for assistive technology, disability mentoring programs, and peer mentors and support for families navigating the IEP or 504 process.

In this mix, collaborations between families and teachers should also not be forgotten. While many teachers and school leaders might feel constrained by their formal titles and duties during school hours, they are often apt to join community groups that advance the needs of their students. Tapping these cross-interest alliances is important to healing relationships between schools and families and leveraging professional expertise for all the right reasons. Finding

172 Lavine, supra note 5. See also Stephen A Rosenbaum, “Une Procédure En Difficulté: A Blueprint for Resolving 'Special' Education Disputes Through a Quasi-Inquisitorial Administrative Process," (this issue (2015) 32 Windsor YB Access Just at 111, arguing that parental knowledge can be valuable in the informal dispute resolution process, but suggesting that complex special education disputes be resolved by binding professional expertise).

173 Kalyanpur et al, supra note 126 at 128.

174 Ibid at 126.

175 Cooper, supra note 79 at 380.

176 Nowell \& Salem, supra note 134 at 313.

177 Nespor \& Hicks, supra note 3 at 316. 
points of overlap in shared values and vision can also help school personnel to transform their own experiences of compassion fatigue or burnout.

As Nespor and Hicks argue, the "organization and communicative frames in which contention unfolds provide resources" for advocates to use to become effective at finding resolutions, raising awareness about educational equity issues, and organizing other parents and community members toward activism. ${ }^{178}$ Therefore, consciousness-raising among parents is something that schools can block or nurture, depending on how much they encourage collaboration from community groups or the development of a sense of community at school.

Indeed, families play an irreplaceable and primary role in modeling for their children what effective communications and advocacy can look like - how change happens without sacrificing self-esteem, identity, or community connections. All of these solutions incorporate community as a basis for mutual self-care and protest by recognizing the limits of individual action and the need for functional dialogues. They leverage individual experiences and interactions to move the education system toward greater sensitivity and responsiveness. They overlap with professionals' experiences of compassion fatigue and burnout in that they start with the effects on the individual to understand structural shifts that must happen, but beyond that starting point, they envision a reinvestment in relationships that the existing literature on compassion fatigue and burnout do not. While that literature might suggest almost a reinvestment in and guarding of the professional self from exhaustion, advocacy fatigue, as I use it here, recognizes the pervasive reality of such exhaustion among marginalized families and proposes ways to make the most of already limited resources.

\section{CONCLUSION}

As Beth Ferri suggests, "If we are to really address what is wrong with special education and general education, we would do well to listen carefully to those most silenced by those who are given the largest platform on which to speak." ${ }^{179}$ Advocacy fatigue should be an expected response to an educational system that often views marginalized students and their families as troublesome and burdensome. This response happens, like compassion fatigue and burnout among teachers and administrators, on both the personal and system level — and will continue to do so unless we are able to innovate in education to reform internal and structural biases. ${ }^{180}$ Schools will need to cultivate "critical dialogue on an inquiry-based culture" and this process begins with the initial training of teachers and principals and follows them over the course of their professional development. ${ }^{181}$ Parents and their students need support and encouragement in demystifying both the process of education, as well as the emotional, material, and physical

$178 \quad$ Ibid at 313.

179 Ferri, supra note 14.

180 Ibid.

181 Zaretsky, supra note 74 at 282. 
effects of discrimination and disenfranchisement that they see in their lives as they come up against education as an institution. ${ }^{182}$

182 Lynn Merlone \& Dolores Moran, "Transition Works: Self-Awareness and Self-Advocacy Skills for Students in the Elementary Learning Center" (2008) 4:4 Teaching Exceptional Children 2 at 3. 